\title{
Rhythm and melody as social signals for infants
}

\author{
Laura K. Cirelli, Sandra E. Trehub, Laurel J. Trainor
}

\author{
Version Post-print/Accepted Manuscript \\ Citation Cirelli, L.K., Trehub, S.E. and Trainor, L.J. (2018), Rhythm and melody \\ (published version) as social signals for infants. Ann. N.Y. Acad. Sci., 1423: 66-72. \\ doi:10.1111/nyas. 13580 \\ Copyright / License C 2018 New York Academy of Sciences \\ Publisher's Statement This is the peer reviewed version of the following article: Cirelli, L.K., \\ Trehub, S.E. and Trainor, L.J. (2018), Rhythm and melody as social \\ signals for infants. Ann. N.Y. Acad. Sci., 1423: 66-72., which has been \\ published in final form at https://doi.org/10.1111/nyas.13580. This \\ article may be used for non-commercial purposes in accordance with \\ Wiley Terms and Conditions for Use of Self-Archived Versions.
}




\author{
Rhythm and melody as social signals for infants \\ Laura K. Cirelli ${ }^{\mathrm{a}}$, Sandra E. Trehub ${ }^{\mathrm{a}}$, Laurel J. Trainor ${ }^{\mathrm{b}, \mathrm{c}, \mathrm{d}}$

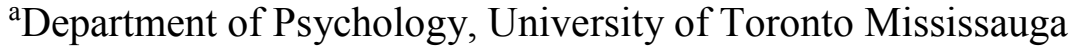 \\ ${ }^{b}$ Department of Psychology, Neuroscience \& Behaviour, McMaster University \\ ${ }^{\mathrm{c}}$ McMaster Institute for Music and the Mind, McMaster University \\ ${ }^{\mathrm{d}}$ Rotman Research Institute, Baycrest Hospital
}

Corresponding author: Laura K. Cirelli, laura.cirelli@utoronto.ca

Short Title: Rhythm and melody as social signals for infants 
Keywords: infants, social development, singing, synchrony, music

\begin{abstract}
Infants typically experience music through social interactions with others. One such experience involves caregivers singing to infants while holding and bouncing them rhythmically. These highly social interactions shape infant music perception and may also influence social cognition and behavior. Moving in time with others, or interpersonal synchrony, can direct infants' social preferences and prosocial behavior. Infants also show social preferences and selective prosociality toward singers of familiar, socially learned melodies. Here we discuss recent studies of the influence of musical engagement on infant social cognition and behavior, highlighting the importance of rhythmic movement and socially relevant melodies.
\end{abstract}




\section{Introduction}

Social interactions are arguably the most important part of an infant's daily life. Human infants are particularly dependent on their caregivers, making social interactions critical for survival. Infants may be drawn to social stimuli for this reason. They prefer faces to other visual stimuli ${ }^{1,2}$ voices to other auditory stimuli, ${ }^{3}$ and they are sensitive to eye-contact with a social partner., ${ }^{4,5}$

Social interactions between infants and caregivers are typically multimodal. Caregivers talk and sing to infants, often in conjunction with touch, movement, and positive facial expressions. Around the world, caregivers sing to infants while rocking or bouncing them to the regular pulse of the music. We argue that these rhythmic and melodic musical interactions are a source of important social information to infants. In support of this claim, we highlight a selection of recent findings from our laboratories and others.

\section{Music perception in infancy - Rhythm and melody}

The primary caregiver is usually the infant's first musical mentor. ${ }^{6}$ Caregivers sing regularly to infants ${ }^{7,8}$ from a small set of songs, each of which is sung repeatedly and relatively consistently in terms of pitch level and tempo. ${ }^{9}$ These ritualized performances become an important part of caregiver-infant interactions. According to parental report, routine singing to infants increases parents' well-being, self-esteem, and reciprocal parent-infant bonding, ${ }^{10}$ while also soothing infants and reducing their distress. ${ }^{11}$ Infants' responses to these musical interactions are shaped by their cumulative exposure to music and by concurrent auditory, motor, and cognitive development. 
Rhythm perception skills allow listeners to track musical sequences in terms of their rhythm (i.e., pattern of sound onsets and offsets), beat (i.e., underlying pulse), and meter (i.e., hierarchical organization of strong and weak beats). The perception of beat and meter is driven in part by bottom-up processes, shaped by top-down processes, and altered by experience (for a review, see Ref. 12). Growing evidence suggests very early sensitivity to the temporal organization of musical sequences. Electroencephalography (EEG) with sleeping newborns reveals sensitivity to the onsets, offsets, and tempo of tone sequences. ${ }^{13}$ Infant brains also respond to the omission of metrically important tones in a rhythm pattern, implying sensitivity to the beat. ${ }^{14}$ Awake, alert infants at 7 and 15 months of age show neural entrainment to the beat and meter of rhythmic patterns. ${ }^{15}$ These findings indicate that the very immature auditory system can extract and organize temporal stimuli.

Behavioral studies reveal that young infants can discriminate changes in tempo ${ }^{16}$ and rhythm. ${ }^{17,18}$ Moreover, they recognize specific rhythm patterns across different tempos. ${ }^{19}$ Infants also categorize melodies on the basis of meter, distinguishing patterns in duple meter (two-beat divisions) from those in triple meter (three-beat divisions). ${ }^{20}$

Incidental exposure to music increases infants' sensitivity to the metrical structures of that culture. Whereas Western 6-month-olds detect meter changes in music with Western or non-Western metrical structure, 12-month-old infants more readily detect meter changes in the context of Western metrical structure. ${ }^{21,22}$ Enriched musical exposure (e.g., parent-infant classes) may accelerate the process of enculturation, ${ }^{23}$ but perception remains flexible in the early years. After limited exposure to music with nonWestern metrical structure, 12-month-olds succeed in detecting the foreign meter 
changes, but adults do not, highlighting infants' perceptual flexibility. ${ }^{22}$ In fact, perceptual flexibility for such metrical distinctions remains evident until 5 years of age. ${ }^{24}$

Movement and the perception of musical timing are intertwined (see for example Refs. 25 -31). Adults are reasonably accurate at aligning their movements to the underlying beat and meter of auditory sequences, but it takes many years for children to achieve comparable sensorimotor synchronization. ${ }^{32,33}$ Although children show tempo flexibility by the preschool years, their accuracy of tapping to a musical beat continues to improve for several years. ${ }^{33,34}$

Infants as young as 5 months of age move rhythmically but not synchronously to rhythmic auditory patterns, also exhibiting modest tempo flexibility. ${ }^{35}$ Moving to music seems to be pleasurable for infants, with displays of positive affect enhanced when infants' movements are more aligned with the auditory input. ${ }^{35}$ Their perception of meter is influenced by passive movement to music (e.g., being bounced or rocked by an adult). After being bounced on every second or third beat of a metrically ambiguous sequence, infants perceive the pattern in groups of two or three, respectively. ${ }^{36}$

Infants extract the melody as well as the rhythm of musical stimuli. After brief exposure to a melody, 2-month-olds distinguish it from an unfamiliar melody ${ }^{37}$ By 5 or 6 months of age, if not earlier, infants recognize a familiarized melody even when transposed or shifted to a different pitch level. ${ }^{38-40}$ Their memory for melodies is also enduring. When 5-month-old infants are exposed to a sung melody for 1 or 2 weeks, they recognize it 8 months later, distinguishing it from an unfamiliar melody sung with the same rhythm and lyrics. ${ }^{41}$ 
The aforementioned studies highlight infants' attention and responsiveness to music. By their first birthday, infants perceive the rhythm, tempo, and metrical groupings of musical sequences, they move to the music they hear, and they recognize melodies months after initial exposure. These abilities enable them to play an active role in musical interactions with their caregivers.

\section{Prosocial consequences of interpersonal synchrony}

Interpersonal synchrony, which is an important social component of musical engagement, is achieved when the movements of one person become temporally aligned with the movements of others. By the time children can synchronize their movements to a beat, they can usually synchronize their rhythmic movements with those of others. ${ }^{42}$ Interpersonal synchrony in non-musical as well as musical (making music, singing or dancing with others) contexts has notable affiliative effects. For example, adults' synchronous singing, tapping, or walking increases subsequent prosocial behavior among participants (for a review, see Ref. 43; for a meta-analysis, see Ref 44).

Infants are also sensitive to the prosocial consequences of interpersonal synchrony. For example, 12-month-olds choose a teddy bear that previously rocked in synchrony with them over one that rocked out-of-synchrony ${ }^{45}$. In addition to showing social preferences for synchronous partners, 14-month-olds behave more prosocially toward synchronously moving adults (for a review, see Ref. 46). The 14-month-olds were held

and bounced gently by one adult (who held them from behind) while an adult who faced them (the target bouncer) bounced in- or out-of-synchrony with the infant. After the bouncing episode, infants' helpfulness toward the target bouncer was assessed by the extent to which they picked up and returned objects that the bouncer dropped 
"accidentally". Infants were significantly more helpful when the target bouncer had exhibited synchronous rather than asynchronous movement, returning more than half of the dropped objects in the former case and less than one third in the latter. ${ }^{47}$ This increased helping was directed specifically to the synchronous movement partnersynchronous and asynchronous bouncing did not influence helping rates directed to a neutral stranger. ${ }^{48}$ If infants observed the experimenter and neutral stranger interacting as "friends," however, they helped the friend of their synchronous movement partner significantly more than the friend of their asynchronous movement partner ${ }^{49}$ Together, these results suggest that synchronous bouncing encourages infants to help the synchronous movement partner and members of that person's social group, but it does not generate indiscriminate helpfulness. Prosocial consequences of synchrony are evident even in the absence of music, but the presence of music enhances infant mood. ${ }^{50}$

Similar prosocial effects of synchrony have been found with older children. For example, 4- to 6-year-olds offer more help to peers after synchronous compared to asynchronous clapping. ${ }^{51}$ Moreover, passive synchrony with a peer on swings generates more cooperative and coordinated peer interaction than asynchronous swinging. ${ }^{52}$ These findings indicate that self-generated and passive synchrony influence childrens' prosociality.

The findings with infants raise the possibility that synchrony helps infants identify in-group members through recognition of self-similarity, as it does for children and adults. ${ }^{53,54}$ Toddlers and preschoolers show social preferences for individuals who share physical similarities or food and toy preferences. ${ }^{55,56} \mathrm{In}$ fact, preschoolers expect 
members of their social group to have the same food preferences as they do. ${ }^{57}$

Synchronous movement may be another social cue for self-similarity.

Individuals can extract important social information merely by observing others interacting synchronously. For example, adults who see two individuals waving or walking in synchrony rate these dyads as more similar to one another and more likely to behave as a social unit than other dyads whose movements are not synchronous. ${ }^{58-60}$

Observing synchrony in others may also shape infants' social expectations. In one study, infants watched displays with three teddy bears. ${ }^{61}$ The centrally located teddy bear rocked in synchrony with one bear and out of synchrony with the other. In the subsequent test phase, the behavior of 15-month-olds indicated that they inferred affiliation only between bears that had moved in synchrony. In another study, 12- to 15-month-olds watched videos of two women bouncing synchronously or asynchronously with one another. ${ }^{62}$ Infants' behavior in the subsequent test phase indicated that friendly interactions between asynchronous bouncers violated their expectations. In other words, observed synchrony and asynchrony signal social attitudes of participants toward one another.

\section{Social importance of rhythmic singing to infants}

Singing is another potential means of conveying social information to infants. Infant-directed (ID) song differs from adult-directed (AD) song in being higher in fundamental frequency, more emotionally expressive, and slower and more regular in

tempo. ${ }^{63-66}$ Infants prefer to listen to ID over AD singing. ${ }^{64,67}$ The rhythmic and melodic features of ID song not only capture infant attention, but also modulate infant arousal. ${ }^{68}$ ID song is also more effective than ID speech at relieving ${ }^{69}$ and preventing ${ }^{70}$ infant 
distress. Furthermore, parents sing in different ways to achieve different social goals, such as playful stimulation or the transition to sleep ${ }^{66}$ and infants respond differently to these styles of singing. ${ }^{71}$

Although ID song captures infant attention by virtue of its acoustic features, song familiarity can confer critical social information. Infants exhibit social preferences for an unfamiliar person who sings a familiar, parent-taught song rather than an unfamiliar song. ${ }^{41}$ In this case, the unfamiliar song shared the lyrics and rhythm of the familiar song, differing only in melody. Interestingly, infants did not exhibit social preferences for singers of familiar melodies if familiarization occurred by interactive video (i.e., performance by an initially unfamiliar woman) or a musical toy, even though they remembered the songs. The implication is that song exposure in a live social context conveys social as well as musical information. The primary caregiver's role in song exposure is likely to be of special importance. As a result, infants may judge an unfamiliar woman who sings a song from the mother's repertoire as being "like mom". Similarly, 11-month-old infants are more likely to accept a toy endorsed by the singer of a familiar song, and looking time at a toy endorsed by the singer of a familiar, parenttaught song is correlated with amount of exposure to this song. ${ }^{72}$

The expressive vocal performances of unfamiliar adults can also affect infants' prosocial tendencies. In a recent study, ${ }^{73}$ an initially unfamiliar adult sang a rhythmic children's song or recited the lyrics of the song expressively, using elaborate visual gestures in both. Baseline levels of infant helping were established by having the unfamiliar adult silently reading a book nearby while parents entertained the infant with books and toys. After the 2.5 -min "stranger exposure" phase, infants participated in a 
helping task with the initially unfamiliar woman, which provided multiple opportunities to retrieve "accidentally" dropped objects. Infant helping in the song or recitation condition significantly exceeded infant helping in the baseline condition, which implies that rhythmic vocal performances of this nature forge connections between performers and the infant audience. Song familiarity also influenced the rate of helping. For infants in the song condition, familiarity with the song "The Ants Go Marching", as reported by parents, predicted helping rates. Specifically, infants helped more as song familiarity increased. ${ }^{73}$

This preference for singers of familiar songs may be rooted in a preference for those who display shared cultural knowledge. Older children prefer peers who know familiar songs over those who know unfamiliar songs, regardless of liking. ${ }^{74}$ For adolescents and adults, shared musical knowledge and preferences can influence friendships and romantic attraction. ${ }^{75-77}$ Historically, shared knowledge was an honest cue of direct social interaction, and it may be a salient signal for group membership. ${ }^{74}$ Accordingly, preferences for singers of familiar songs in infancy, those who know familiar songs in childhood, and those who know and like familiar songs in adolescence and adulthood, may be driven by a bias for potential members of our social group.

\section{Conclusion}

The studies reported here are consistent with the view that infants use interpersonal synchrony and song familiarity to selectively direct their social behavior (See Table 1 for a summary). According to the partner choice model of prosociality, ${ }^{78}$ directing prosociality to "better" social partners is an adaptive social strategy. Infants may direct their attention preferentially to suitable social partners by seeking out those who are more 
likely to be part of their social group. For example, infants show social preferences for speakers of their native language or dialect, who are more likely to be part of a favored social group. ${ }^{79}$ Here we argue that moving synchronously with infants and singing familiar melodies to them may also signal group membership, highlighting the social relevance of rhythm and melody in musical engagement.

These signals for group membership also help infants make sense of the social world around them. When infants observe others moving in or out of synchrony with one another, they use this information to predict affiliation. ${ }^{61,62}$ An interesting question for future research is whether infants expect two singers of the same melody to affiliate more than singers of different melodies.

What is also unclear is whether the prosocial consequences of synchronous movement or singing are short-lived (e.g., evident immediately after the exposure phase) or longer lasting (e.g., evident in subsequent days or weeks). If such interactions signal partner quality, then they may have continuing influences on infant social behavior. It remains to be determined whether synchronous movement or singing a familiar song contributes to the memorability of the initially unfamiliar person who engages in such behavior. If it does, then infants might exhibit prosocial behavior toward such individuals on future occasions.

In sum, musical engagement for infants is largely social and multimodal. When caregivers hold infants and gently rock them while singing a familiar song, they are conveying complex sensory, social, and affective information. These multimodal, interactive musical experiences are likely to have greater impact on infants than passive exposure to recorded music ${ }^{11}$. Although caregivers play recorded music at home ${ }^{80}$, it 
often supplements interactive musical play rather than replacing it . Musical interactions between caregivers and infants are likely to enhance the bonds between them, setting the stage for social cognitive consequences of musical engagement in the years ahead.

\section{Acknowledgements}

This research was funded by grants from the Natural Sciences and Engineering Research Council of Canada (one to ST, the other to LT) and by a postdoctoral fellowship from the Social Sciences and Humanities Research Council of Canada to LC.

\section{Competing Interests}

The authors have no competing interests. 


\section{References}

1. Mondloch, C.J., T.L. Lewis, D.R. Budreau, et al. 1999. Face perception during early infancy. Dev. Sci. 10: 419-422.

2. Johnson, M.H., S. Dziurawiec, H. Ellis, et al. 1991. Newborns' preferential tracking of face-like stimuli and its subsequent decline. Cognition 40:1-19.

3. Vouloumanos, A. \& J.F. Werker. 2007. Listening to language at birth: evidence for a bias for speech in neonates. Dev. Sci. 10: 159-164.

4. Farroni, T., G. Csibra, F. Simion, et al. 2002. Eye contact detection in humans from birth. Ann. N.Y. Acad. Sci. 99: 9602-9605.

5. Farroni, T., M.H. Johnson \& G. Csibra. 2004. Mechanisms of eye gaze perception during infancy. J. Cogn. Neurosci. 16: 1320-1326.

6. Trehub, S.E. \& H.R. Gudmundsdottir. 2015. "Mothers as singing mentors for infants." In The Oxford Handbook of Singing. G. Welch, D. Howard, \& J. Nix, Eds.:online publication. Oxford University Press.

7. de l'Etoile, S.K. 2006. Infant behavioral responses to infant-directed singing and other maternal interactions. Infant Behav. Dev. 29: 456-470.

8. Trehub, S.E., A.M. Unyk, S.B. Kamenetsky, et al. 1997. Mothers' and fathers' singing to infants. Dev. Psychol. 33: 500-507.

9. Bergeson, T. \& S.E. Trehub. 2002. Absolute pitch and tempo in mothers' songs to infants. Psychol. Sci. 13: 72-75.

10. Fancourt, D. \& R. Perkins. 2017. Maternal engagement with music up to nine months post-birth: findings from a cross-sectional study in England. Psychol. 
Music. Advance online publication, doi: 10.1177/0305735617705720.

11. Gerry, D., A. Unrau \& L.J. Trainor. 2012. Active music classes in infancy enhance musical, communicative and social development. Dev. Sci. 15: 398-407.

12. Repp, B.H. \& Y. Su. 2013. Sensorimotor synchronization: a review of recent research (2006-2012). Psychon. Bull. Rev. 20: 403-452.

13. Háden, G.P., H. Honing, M. Török, et al. 2015. Detecting the temporal structure of sound sequences in newborn infants. Int. J. Psychophysiol. 96: 23-28.

14. Winkler, I., G.P. Háden, O. Ladinig, et al. 2009. Newborn infants detect the beat in music. Ann. N.Y. Acad. Sci. 106: 2468-2471.

15. Cirelli, L.K., C. Spinelli, S. Nozaradan, et al. 2016. Measuring neural entrainment to beat and meter in infants: effects of music background. Front. Neurosci. 10: 1229.

16. Baruch, C. \& C. Drake. 1997. Tempo discrimination in infants. Infant Behav. Dev. 20: $573-577$.

17. Chang, H. \& S.E. Trehub. 1977. Infants' perception of temporal grouping in auditory patterns. Child Dev. 48: 1666-1670.

18. Demany, L., B. McKenzie \& E. Vurpillot. 1977. Rhythm perception in early infancy. Nature 266: 718-719.

19. Trehub, S.E. \& L.A. Thorpe. 1989. Infants' perception of rhythm: categorization of auditory sequences by temporal structure. Can. J. Psychol. 43: 217-229.

20. Hannon, E.E. \& S.P. Johnson. 2005. Infants use meter to categorize rhythms and melodies: implications for musical structure learning. Cogn. Psychol. 50: $354-$ 377. 
21. Hannon, E.E. \& S.E. Trehub. 2005. Metrical categories in infancy and adulthood. Psychol. Sci. 16: 48-55.

22. Hannon, E.E. \& S.E. Trehub. 2005. Tuning in to musical rhythms: infants learn more readily than adults. Ann. N.Y. Acad. Sci. 102: 12639-12643.

23. Gerry, D.W., A.L. Faux \& L.J. Trainor. 2010. Effects of Kindermusik training on infants' rhythmic enculturation. Dev. Sci. 13: 545-551.

24. Hannon, E.E., C.M. Vanden Bosch der Nederlanden \& P. Tichko. 2012. Effects of perceptual experience on children's and adults' perception of unfamiliar rhythms. Ann. N.Y. Acad. Sci. 1252: 92-99.

25. Butler, B.E. \& L.J. Trainor. 2015. The musician redefined: a behavioral assessment of rhythm perception in professional club DJs. Timing Time Percept. 3: $116-132$.

26. Manning, F. \& M. Schutz. 2013. "Moving to the beat" improves timing perception. Psychon. Bull. Rev. 20: 1133-1139.

27. Phillips-Silver, J. \& L.J. Trainor. 2007. Hearing what the body feels: auditory encoding of rhythmic movement. Cognition 105: 533-546.

28. Zatorre, R.J., J.L. Chen \& V.B. Penhune. 2007. When the brain plays music: auditory-motor interactions in music perception and production. Nat. Rev. Neurosci. 8: 547-58.

29. Patel, A. \& J. Iversen. 2014. The evolutionary neuroscience of musical beat perception: the Action Simulation for Auditory Prediction (ASAP) hypothesis. Front Syst. Neurosci. 8: 57.

30. Trainor, L.J. 2007. Do preferred beat rate and entrainment to the beat have a 
common origin in movement? Empir. Musicol. Rev. 2: 17-20.

31. Merchant, H., J. Grahn, L.J. Trainor, et al. 2015. Finding the beat: a neural perspective across humans and non-human primates. Philos. Trans. R. Soc. B. Biol. Sci. 370: 20140093-20140093.

32. Eerola, T., G. Luck \& P. Toiviainen. 2006. An investigation of preschoolers' corporeal synchronization with music. Proc. 9th Int. Conf. Music Percept. Cogn. $472-476$.

33. McAuley, J.D., M.R. Jones, S. Holub, et al. 2006. The time of our lives: life span development of timing and event tracking. J. Exp. Psychol. Gen. 135: 348-367.

34. Drake, C., M.R. Jones \& C. Baruch. 2000. The development of rhythmic attending in auditory sequences: attunement, referent period, focal attending. Cognition 77: 251-288.

35. Zentner, M. \& T. Eerola. 2010. Rhythmic engagement with music in infancy. Ann. N.Y. Acad. Sci. 107: 5768-5773.

36. Phillips-Silver, J. \& L.J. Trainor. 2005. Feeling the beat: movement influences infant rhythm perception. Science 308: 1430.

37. Plantinga, J. \& L.J. Trainor. 2009. Melody recognition by two-month-old infants. J. Acoust. Soc. Am. 125: EL58-62.

38. Chang, H.W. \& S.E. Trehub. 1977. Auditory processing of relational information by young infants. J. Exp. Child Psychol. 24: 324-331.

39. Plantinga, J. \& L.J. Trainor. 2005. Memory for melody: infants use a relative pitch code. Cognition 98: 1-11.

40. Tew, S., T. Fujioka, C. He, et al. 2009. Neural representation of transposed 
melody in infants at 6 months of age. Ann. N.Y. Acad. Sci. 1169: 287-290.

41. Mehr, S.A., L.A. Song \& E.S. Spelke. 2016. For 5-month-old infants, melodies are social. Psychol. Sci. 27: 486-501.

42. Endedijk, H.M., V.C.O. Ramenzoni, R.F.A. Cox, et al. 2015. Development of interpersonal coordination between peers during a drumming task. Dev. Psychol. 51: 714-721.

43. Tarr, B., J. Launay \& R.I.M. Dunbar. 2014. Music and social bonding: "selfother" merging and neurohormonal mechanisms. Front. Psychol. 5: 1096.

44. Mogan, R., R. Fischer \& J.A. Bulbulia. 2017. To be in synchrony or not? a metaanalysis of synchrony's effects on behavior, perception, cognition and affect. $J$. Exp. Soc. Psychol. 72: 13-20.

45. Tunçgenç, B., E. Cohen \& C. Fawcett. 2015. Rock with me: the role of movement synchrony in infants' social and nonsocial choices. Child Dev. 86: 976-984.

46. Cirelli, L.K. 2018. How interpersonal synchrony facilitates early prosocial behavior. Curr. Opin. Psychol. 20: 35-39.

47. Cirelli, L.K., K.M. Einarson \& L.J. Trainor. 2014. Interpersonal synchrony increases prosocial behavior in infants. Dev. Sci. 17: 1003-1011.

48. Cirelli, L.K., S.J. Wan \& L.J. Trainor. 2014. Fourteen-month-old infants use interpersonal synchrony as a cue to direct helpfulness. Philos. Trans. R. Soc. B. Biol. Sci. 369: 20130400-20130400.

49. Cirelli, L.K., S.J. Wan \& L.J. Trainor. 2016. Social effects of movement synchrony: increased infant helpfulness only transfers to affiliates of synchronously moving partners. Infancy 21: 807-821. 
50. Cirelli, L.K., S.J. Wan, C. Spinelli, et al. 2017. Effects of interpersonal movement synchrony on infant helping behaviors: Is music necessary? Music Percept. 34: 319-326.

51. Tunçgenç, B. \& E. Cohen. 2016. Interpersonal movement synchrony facilitates pro-social behavior in children's peer-play. Dev. Sci. Advance online publication, doi:10.1111/desc. 12505 .

52. Rabinowitch, T.C. \& A.N. Meltzoff. 2017. Synchronized movement experience enhances peer cooperation in preschool children. J. Exp. Child. Psychol. 160: $21-$ 32.

53. Rabinowitch, T-C. \& A. Knafo-Noam. 2015. Synchronous rhythmic interaction enhances children's perceived similarity and closeness towards each other. PLoS One, 10: e 0120878.

54. Valdesolo, P. \& D. Desteno. 2011. Synchrony and the social tuning of compassion. Emotion 11: 262-266.

55. Fawcett, C.A. \& L. Markson. 2010. Similarity predicts liking in 3-year-old children. J. Exp. Child Psychol. 105: 345-358.

56. Gerson, S.A., H. Bekkering \& S. Hunnius. 2017. Do you do as I do? young toddlers prefer and copy toy choices of similarly acting others. Infancy 22: 5-22.

57. Gruber, T., A. Deschenaux, A. Frick, et al. 2017. Group membership influences more social identification than social learning or overimitation in children. Child Dev. Advance online publication, doi:10.1111/cdev.12931

58. Lakens, D. 2010. Movement synchrony and perceived entitativity. J. Exp. Soc. Psychol. 46: 701-708. 
59. Lakens, D. \& M. Stel. 2011. If they move in sync, they must feel in sync: movement synchrony leads to attributions of rapport and entitativity. Soc. Cogn. 29: $1-14$.

60. Edelman, L.L. \& K.E. Harring. 2015. Music and social bonding: the role of nondiegetic music and synchrony on perceptions of videotaped walkers. Curr. Psychol. 34: 613-620.

61. Fawcett, C. \& B. Tunçgenç. 2017. Infants' use of movement synchrony to infer social affiliation in others. J. Exp. Child Psychol. 160: 127-136.

62. Cirelli, L.K., S.J. Wan, T. Johanis, \& L.J. Trainor. In press. Infants' use of interpersonal asynchrony as a signal for third-party affiliation. Music \& Science.

63. Nakata, T. \& S.E. Trehub. 2011. Expressive timing and dynamics in infantdirected and non-infant-directed singing. Psychomusicology: Music Mind Brain 21:130-138.

64. Trainor, L.J. 1996. Infant preferences for infant-directed versus noninfant-directed playsongs and lullabies. Infant Behav. Dev. 19: 83-92.

65. Trehub, S.E. \& L.J. Trainor. 1998. Singing to infants: lullabies and play songs. Adv. Infancy Res. 12: 43-77.

66. Trainor, L.J., E.D. Clark, A. Huntley, et al. 1997. The acoustic basis of preferences for infant-directed singing. Infant Behav. Dev. 20: 383-396.

67. Masataka, N. 1999. Preference for infant-directed singing in 2-day-old hearing infants of deaf parents. Dev. Psychol. 35: 1001-1005.

68. Shenfield, T., S.E. Trehub \& T. Nakata. 2003. Maternal singing modulates infant arousal. Psychol. Music. 31: 365-375. 
69. Ghazban, N. 2013. Emotion regulation in infants using maternal singing and speech. PhD dissertation. Ryerson University. Toronto.

70. Corbeil, M., S.E. Trehub \& I. Peretz. 2015. Singing delays the onset of infant distress. Infancy 21: 373-391.

71. Rock, A.M.L., L.J. Trainor \& T.L. Addison. 1999. Distinctive messages in infantdirected lullabies and play songs. Dev. Psychol. 35: 527-534.

72. Mehr, S.A. \& E.S. Spelke. 2017. Shared musical knowledge in 11-month-old infants. Dev. Sci. Advance online publication, doi: 10.1111/desc.12542

73. Cirelli, L.K. \& S.E. Trehub. 2017. Infant prosocial behavior toward singing and non-singing partners. Paper presented at: Society for Music Perception and Cognition, San Diego, CA.

74. Soley, G., E.S. \& Spelke. 2016. Shared cultural knowledge: Effects of music on young children's social preferences. Cognition. 148:106-116.

75. Rentfrow, P. J. \& S.D. Gosling. 2006. Message in a ballad: The role of music preferences in interpersonal perception. Psychol. Sci. 17: 236-242.

76. Selfhout, M. H., S.J. Branje, T.F. ter Bogt, \& W.H. Meeus. 2009. The role of music preferences in early adolescents' friendship formation and stability. $J$. Adolescence. 32: 95-107.

77. Zillmann, D. \& A. Bhatia. 1989. Effects of associating with musical genres on heterosexual attraction. Commun. Res. 16: 263-288.

78. Kuhlmeier, V. A., K.A. Dunfield \& A.C. O’Neill. 2014. Selectivity in early prosocial behavior. Front. Psychol. 5: 836.

79. Kinzler, K.D., E. Dupoux \& E.S. Spelke. 2007. The native language of social 
cognition. Ann. N.Y. Acad. Sci. 104:12577-12580.

80. Young, S. 2008. Lullaby light shows: everyday musical experience among undertwo-year-olds. Int. J.Music Educ. 26: 33-46. 